\title{
Entrepreneurship
}

Jul a Dez $2018-$ v.2 - n.2

ISSN: 2595-4318

This article is also available online at: www.sustenere.co

\section{Controle e gerenciamento na gestão de estoque nas empresas}

Considerando a grande concorrência entre as empresas diante do cenário globalizado, as organizações precisam estar atentas a todos os ativos da empresa e o estoque simboliza um grande valor investido e que a princípio não gera lucro, mas a falha no controle e gerenciamento da gestão de estoque pode gerar prejuízo e deixar de ser uma vantagem competitiva. Sendo assim, o artigo tem como objetivo geral analisar como a gestão de estoques pode ajudar na lucratividade organizacional das empresas. Os objetivos específicos pretendem identificar os níveis de estoque de segurança de acordo com a demanda e o tempo de ressuprimento; abordar periodicidade de inventários, sem impactar na confiabilidade do estoque contábil; compreender o volume de estoque em busca da otimização e entender os métodos utilizados nos atendimentos das solicitações dos clientes, em busca de um retorno rápido e com eficiência nos pedidos e prestação dos serviços. Para atingir estes objetivos utilizou-se o método de pesquisa qualitativo, de cunho descritivo-exploratório. E abordando os conceitos de estoque, quais os tipos e os custos de estoque, administração de estoque com os objetivos e funções, os princípios e os sistemas de controle de estoque e a classificação dos materiais de acordo com a curva ABC.

Palavras-chave: Estoque; Administração; Princípios; Sistemas.

\section{Control and management in business stock management}

Considering the great competition between companies in the face of the globalized scenario, organizations need to be attentive to all the assets of the company and the stock symbolizes a great value invested and that at first does not generate profit, but the failure in the control and management of stock management can generate loss and cease to be a competitive advantage. Thus, the article aims to analyze how inventory management can help in the organizational profitability of companies. The specific objectives are to identify the security stock levels according to the demand and the resupply time; address periodicity of inventories, without impacting the reliability of the accounting stock; understand the volume of inventory in search of optimization and understand the methods used to meet the requests of customers, seeking a fast and efficient return on orders and service delivery. To achieve these objectives, a qualitative research method was used, with a descriptive-exploratory approach. And approaching inventory concepts, inventory types and costs, stock management with objectives and functions, stock control principles and systems, and material classification according to the $A B C$ curve.

Keywords: Stock; Administration; Principles; Systems.

Topic: Planejamento, Estratégia e Competitividade

Reviewed anonymously in the process of blind peer.
Received: $\mathbf{2 1 / 0 2 / 2 0 1 8}$

Approved: $10 / 04 / 2018$
Wanessa dos Santos Souza (ib)

Faculdade Uninassau Aracaju, Brasil

http://lattes.cnpq.br/3528601182938529

http://orcid.org/0000-0002-8988-1689

souza-nessa@hotmail.com

Alvani Bomfim de Sousa Júnior (iD)

Faculdade Uninassau Aracaju, Brasil

http://lattes.cnpq.br/6358502728889050

http://orcid.org/0000-0002-8714-4175

alvanijunior@yahoo.com.br

\section{Referencing this:}

SOUZA, W. S.; SOUSA JÚNIOR, A. B.. Controle e gerenciamento na gestão de estoque nas empresas. Entrepreneurship, v.2, n.2, p.54-67, 2018. DOI: http://doi.org/10.6008/CBPC2595-4318.2018.002.0005

DOI: 10.6008/CBPC2595-4318.2018.002.0005 


\section{INTRODUÇÃO}

O presente estudo tem por finalidade analisar a gestão de estoque nas empresas. Avaliando a gestão, custos, controles, sistemas e classificação dos estoques. Para que através do estoque as empresas possam aumentar a lucratividade organizacional, diminuir as despesas com manutenções de estoques e torna-se mais competitiva no mercado. Qualquer tipo de organização, seja ela, privada, pública ou sem fins lucrativos poderá utilizar a gestão de estoque como uma vantagem competitiva.

A natureza competitiva do mundo globalizado evidenciou a importância de as empresas terem profissionais altamente qualificados no gerenciamento dos seus processos internos. A gestão de estoques está entre os processos mais importantes para o sucesso de uma organização. Entretanto, apesar de absorverem parte substancial de seu orçamento operacional, os estoques não agregam valores aos produtos. A minimização do nível de estoques tem sido um diferencial competitivo ao impactar diretamente sobre a eficiência organizacional e a redução dos custos.

A gestão de estoques nas empresas tem grande importância para um fluxo de materiais enxuto, onde seja garantido o bom atendimento ao cliente final sem que haja desperdícios e estoques em excesso ao longo da cadeia, focando sempre a lucratividade organizacional.

O estoque se destaca como um processo para reduções de custos porque, além de ser uma parcela relevante destes custos, tem um grande impacto sobre o retorno do investimento dos empresários ou acionistas. Enquanto as taxas de juros e a escassez de recursos pressionam os estoques para baixo a incerteza da demanda força as empresas a manterem um estoque de segurança, a fim de evitar problemas com estoque, e garantir a sobrevivência no momento de pico.

O pensamento de alguns autores que fundamentaram com suas ideias e conceitos, como Werkema que instituiu uma nova filosofia de gerenciamento adequada à realizada atual. Shingo refere-se ao sistema de estruturação, cálculos e decisões com base em estoques existentes. Womack enfoca as dificuldades da produção (SLACK et al., 2007) empurrada referindo-se à quantidade de estoques intermediários e filas de espera de materiais em processamento.

Em vista do cenário supra exposto, desenha-se como objetivo central do presente artigo, analisar como a gestão de estoques pode ajudar na lucratividade organizacional das empresas. A fim de traçar um caminho coerente para o desenvolvimento do tema, elencam-se como objetivos específicos: identificar os níveis de estoque de segurança de acordo com a demanda e o tempo de ressuprimento; abordar periodicidade de inventários, sem impactar na confiabilidade do estoque contábil; compreender o volume de estoque em busca da otimização e entender os métodos utilizados nos atendimentos das solicitações dos clientes, em busca de um retorno rápido e com eficiência nos pedidos e prestação dos serviços.

Sendo assim, diante de toda as transformações ocorridas no mercado, à gestão de estoque destacase como um diferencial competitivo, buscando atender seus clientes no menor tempo possível e ao mesmo tempo eliminar desperdícios e reduzir custos. Como a gestão de estoque influência na lucratividade organizacional das empresas de Auto Center Peças e Acessórios do estado de Sergipe? 
O presente estudo justifica-se, por falta de conhecimento da demanda futura dos consumidores e indisponibilidade dos suprimentos a qualquer momento, faz-se necessário os estoques nas empresas. Eles garantem a disponibilidade das mercadorias no momento que elas são solicitadas pelos clientes e minimizam os custos de produção e/ ou distribuição. Conforme Chiavenato (2005), "[...] Estoque é a composição de materiais, materiais em processamento, materiais semiacabados, materiais acabados, que não é utilizada em determinado momento na empresa, mais que precisa existir em função de futuras necessidades".

Com a alta competitividade e a maior exigência do consumidor as empresas necessitam se adaptarem rapidamente à tendência, melhorar suas performances e agregar valores aos seus serviços e produtos. E a gestão de estoque entra com a função de deixar as empresas no nível em que se exige o mercado, garantindo maior disponibilidade de produto ao consumidor, com o menor nível de estoque possível. Estoques excessivos significam gastar dinheiro à toa, é assumir custo que não retorna benefício algum.

Hoje as empresas procuram a obtenção de uma vantagem competitiva em relação a seus concorrentes, e a oportunidade de atendê-los prontamente, no momento e na quantidade desejada, é grandemente facilitada com a administração eficaz dos estoques.

\section{METODOLOGIA}

A pesquisa eleita seguirá metodologia exploratória, com a utilização de bibliografia como procedimento de pesquisa (GIL, 2008). A pesquisa bibliográfica procura explicar e discutir um tema com base em referências teóricas publicadas em livros, revistas, periódicos e outros. Busca também, conhecer e analisar conteúdos científicos sobre determinado tema (MARTINS, 2001).

Pode acrescentar a este acervo as consultas a bases de dados, periódicos e artigos indexados com o propósito de melhorar a pesquisa. Este tipo de pesquisa tem como finalidade colocar o pesquisador em contato direto com tudo o que foi escrito, dito ou filmado sobre determinado assunto (MARCONI et al., 2007).

Sendo assim, segundo os autores acima, a pesquisa bibliográfica não é apenas uma repetição do que já foi dito ou escrito sobre certo assunto, mas sim, possibilita a avaliação de um tema sob nova abordagem, produzindo novas conclusões. Demo (2000), completa dizendo que a ideia da pesquisa é de induzir o contato pessoal do aluno com as teorias, pôr da leitura, levando à interpretação própria.

O método de pesquisa utilizado é o qualitativo através descritivo-exploratório, apoiando-se em resultados através de percepções e análises. Ela descreve a complexidade do problema e a interação de variáveis. De acordo com Neves (1996), a pesquisa qualitativa não busca enumerar ou medir eventos. Ela serve para obter dados descritivos que expressam os sentidos dos fenômenos. Exploratória, pois, segundo Severino (2007) "busca apenas levantar informações sobre determinado objeto, delimitando assim um campo de trabalho, mapeando as condições de manifestação desse objeto"; descritiva, por utilizar técnicas de coleta de dados e preocupar-se em analisá-los e interpretá-los. 


\section{REVISÃO TEÓRICA}

\section{Estoques}

A globalização da economia vem produzindo significativas mudanças na forma de condução dos negócios. No cenário atual, clientes exigem um alto nível de serviço, pedidos mais frequentes, e trabalham no sentido de manter os níveis de estoque exatamente na medida de suas necessidades. Os consumidores, por sua vez, querem maior variedade e conformidade nos produtos. Fidelidade a produtos e serviços não se encontra mais presente nos processos de compra. Ballou (2006) diz que estoques são acumulações de matérias-primas, suprimentos, componentes, materiais em processo e produtos acabados que surgem em numerosos pontos do canal de produção e logística das empresas. Conforme Dias (2010):

Gestão de estoques está pautada na previsão do consumo do material. A previsão de consumo ou da demanda estabelece estimativas futuras dos produtos acabados comercializados e vendidos. Estabelece, portanto, quais produtos, quanto desses produtos e quando serão comprados pelos clientes.

Segundo Slack et al. (1997) entende que:

O estoque e definido como acumulação de recursos materiais em um sistema de transformação. Algumas vezes estoque também e usado para descrever qualquer recurso armazenado. Não importa o que está sendo armazenado como estoque, ou onde ele está posicionado na operação, ele existira porque existe uma diferença de ritmo ou de taxa entre fornecimento e demanda.

Os sistemas de Planejamento de Materiais preocupam-se basicamente com o dimensionamento correto dos estoques. Reduções de custo ou maximização de lucro, provenientes de uma perfeita adequação dos estoques ao tamanho das necessidades, podem ser alcançadas através da utilização de métodos e sistemas de planejamento e controle especialmente projetados para esta finalidade.

Logo, compreende-se então que a gestão do estoque é estritamente necessária em uma organização, pois ela juntamente com os demais departamentos é todo o funcionamento de uma empresa. Além de ressaltar que é de extrema importância desenvolver um processo no gerenciamento de estoque da organização destrinchando num controle mais rígido do negócio, pois uma empresa que depende de produção ou comercio não pode sobreviver sem um bom sistema de gerencialmente de estoque.

\section{Tipos de Estoques}

Dividir o estoque em tipos facilita o controle. Existem diversas formas diferentes de classificação de estoques, conforme a finalidade de controle. Segundo Ballou (2006), existem cinco categorias nas quais situar os estoques: estoque no canal, estoques para fins de especulação, estoques regular ou cíclica, estoque de segurança e estoque obsoleto, morto ou evaporado.

Observamos também que Chiavenato (2005), classifica os estoques de acordo com os mesmos critérios de classificação de materiais. Estoque de matérias-primas: constituído pelos insumos e materiais básicos que ingressam no processo produtivo da empresa. Estoque de materiais em processamento ou em vias: constituído de materiais que estão sendo processados ao longo das diversas seções do processo 
produtivo. Para Dias (2010), os principais tipos de estoque, encontrados em uma empresa industrial, são: matérias-primas, produtos em processo, produtos acabados, peças de manutenção e materiais auxiliares.

\section{Objetivos e Funções de Estoque}

Segundo Dias (2010), a função da Administração e Estoques é maximizar o efeito lubrificante do feedback de vendas e o ajuste do planejamento e programação da produção. A administração de estoques não se preocupa somente com o fluxo diário entre vendas e compras, mas também com a relação de encarar lógica entre vendas e compras, como também a relação lógica entre cada integrante deste fluxo, e traz uma mudança na forma tradicional de encarar o estoque nas suas diferentes formas, pois trata de um novo sistema de organização. Conforme os autores, as deficiências do controle de estoque normalmente são mostradas por reclamações contra sintomas específicos e não por críticas diretas a todo o sistema.

\section{Administração de Estoques}

Os estoques representam a maior parte de uma organização, onde ele tem função de suprir a necessidades de demanda, sendo responsável pela definição do planejamento de controle de estoques. Para Arnold (1999) os estoques são materiais e suprimentos disponíveis tanto para a venda quanto para o processo produtivo. São partes do processo de planejamento e fornece uma reserva intermediaria para dar conta de diferenças nas taxas de demanda e de produção.

Já Tubino (2000) para administrar os estoques, há a necessidade de diferenciá-los quanto a suas importâncias relativas, definir tamanhos de lotes de reposição, estabelecer modelos que permitam operacionalizar seus controles e dimensionar estoques de segurança. Os estoques devem representar uma grande vantagem dentro da organização se bem administrados, exigindo todas as atividades envolvidas sejam integradas e controladas num sistema em quantidades e valores, ou seja, uma interação entre todos os setores.

\section{Princípios do Controle de Estoques}

Segundo Dias (2010), para organizar um setor de controle de estoques, inicialmente descrever seus objetivos principais, que são: a) determinar "o que" deve permanecer em estoque: número de itens; b) determinar "quando" se devem reabastecer os estoques: periodicidade; c) determinar "quanto" de estoque será necessário para um período predeterminado: quantidade de compra; d) acionar o departamento de compras para executar aquisição de estoque: solicitação de compras; e) receber, armazenar e guardar os materiais estocados de acordo com as necessidades; $\mathrm{f}$ ) controlar os estoques em termos de quantidade e valor; g) fornece informações sobre a posição do estoque; h) manter inventários periódicos para avaliação das quantidades e estados dos materiais estocados; i) Identificar e retirar do estoque os itens obsoletos e danificados.

Nos estoques de matéria-prima e materiais auxiliares segundo Severo Filho (2006), encontramos materiais secundários, como componentes que irão integrar o produto. São usualmente compostos por 
materiais brutos destinados a transformação. O estoque de produtos em processo segundo Severo Filho (2006), baseia-se essencialmente em todos os artigos solicitadas necessários à fabricação ou montagem do produto, que se encontram nas várias fases de produção.

O estoque de produtos acabados é composto pelo produto que teve seu processo de fabricação finalizado. Em empresas comerciais é chamado de estoque de mercadorias. Usualmente são materiais que se encontram em depósitos próprios para expedição. São formados por materiais ou produtos em condições de serem vendidos (SEVERO FILHO, 2006).

O estoque operacional ou de peças de manutenção é o tipo de estoque destinado a evitar possíveis interrupções na produção por defeito ou quebra de algum equipamento. É constituído por lubrificantes ou quaisquer materiais destinados à manutenção, substituição ou reparos tais como componentes ou peças sobressalentes (SEVERO FILHO, 2006).

Estoque de segurança ou mínimo são quantidades guardadas para garantir o andamento do processo produtivo caso ocorram aumento na demanda do item por parte do processo ou atraso no abastecimento futuro (Cabral, 1998). De acordo com Garcia et al. (2006):

Os estoques de segurança impedem que ocorram problemas inesperados em alguma fase
produtiva interrompendo as atividades sucessivas de atendimento da demanda. A
existência de estoques de segurança em uma unidade fabril, evita que o processo produtivo
pare em caso de uma avaria, alimentando as máquinas subsequentes durante a reparação.
São ainda utilizados para salvaguardar uma empresa de incertezas nas suas operações
logísticas. Lead-times (tempo entre colocar e receber um pedido), procura dos clientes, e
quantidades recebidas são exemplas de fatores que podem apresentar variações não
esperados.

Existem diversos aspectos que devem ser definidos, antes de se montar um sistema de controle de estoque. Um deles referente aos diferentes tipos de estoque existentes na empresa, outro diz respeito aos diferentes pontos de vista quanto ao nível adequado de estoque que deve ser mantido para atender as necessidades. Um terceiro ponto seria atender o capital necessário envolvido.

\section{Custos}

Segundo Kaplan (citado por NAKAGAWA, 1993), "os sistemas de custeios datam, basicamente, de há mais de um século e foram desenvolvidos com o objetivo de gerarem informações sobre a oportunidade de melhoria de desempenho das empresas, em termos de resultados econômicos".

Para a contabilidade de custos departamentalização é o critério mais eficaz para uma distribuição dos custos. Com isto cada departamento pode ser dividido em mais de um centro de custos. Logo, a sua apropriação dos custos dos produtos, é também necessário que todos custos estejam nos departamentos de produção. É necessário ainda que todos os custos dos departamentos de serviços sejam rateados de forma que recaiam sobre os de produção. Conforme Leone (1997) "a departamentalização é resultado de um feito pela administração da empresa, que leva em conta as várias especialidades e as diversas atividades ou funções. 


\section{Custos de Estoques}

Segundo Dias (2005), todo e qualquer armazenamento gera determinados custos, que são: juros, depreciação, aluguel, equipamento de movimentação, deterioração, obsolescência, seguro, salários e convecção. Já Ballou (2006), as três classes gerais de custos importantes para a determinação da política de estoque são: os custos de aquisição, de manutenção e de falta de estoques. São custos permanentemente em conflito, ou em compensação, entre si. Com o objetivo de determinar a quantidade do pedido de reposição de um item no estoque.

Todos eles podem ser agrupados em diversas modalidades, onde existem duas variáveis que aumentam esses custos, que são a quantidade em estoque e o tempo de permanência em estoque. Grandes quantidades em estoque somente poderão ser movimentadas com a utilização de mais pessoal, ou então, com o maior uso de equipamento, tendo como consequência a elevação destes custos. No caso de um menor volume em estoque, o efeito é exatamente o contrário, com exceção dos materiais de grandes dimensões.

\section{Custos de Aquisição}

Para Ballou (2006), os custos de aquisição podem incluir o preço, ou custo de fabricação do produto conforme as quantidades pedidas; o custo da preparação do processo de produção; o custo do processamento de um pedido pelos departamentos de contabilidade e compras; o custo de transmissão do pedido ao ponto de suprimento, normalmente pela utilização de correios ou meios eletrônicos; o custo do transporte do pedido quando as tarifas de transporte não fazem parte de compra dos produtos; e o custo de qualquer manuseio ou processamento dos produtos no ponto de recepção.

Alguns custos de aquisição são fixos por pedido e não variam de acordo com o tamanho do pedido. Outros, como transporte, produção e manuseio dos materiais, variam de acordo com o tamanho dos pedidos. Cada um deles exige tratamento analítico ligeiramente diferente. De acordo com Garcia et al. (2006):

Custo de pedido são custos referentes a uma nova encomenda, podendo esses custos ser tanto variáveis como fixos. Os custos fixos associados a um pedido são o envio da encomenda, receber essa mesma encomenda e inspeção. $O$ exemplo principal de custo variável é o preço unitário de compra dos artigos encomendados.

Sendo assim, conforme os autores abordaram, o custo com aquisição pode ser fixo ou variável dependendo da fase no processo de aquisição e deverá ser tratado de forma diferente devido a influência que pode gerar no preço final do produto. A importância de identificar a melhor alternativa de tipo de transporte a ser utilizado, já que ele irá representar o principal custo variável adicional ao preço do produto.

\section{Custo de Manutenção}

Segundo Ballou (2006), os custos de manutenção dos estoques são aqueles resultantes do armazenamento, ou propriedade, de produtos durante um determinado período, proporcionais a média das quantidades de mercadorias disponíveis. Conforme Garcia et al. (2006):

Custos de manutenção de estoques são custos proporcionais a quantidade armazenada e ao tempo que está fica em estoque. Um dos custos mais importante é o custo de oportunidade do capital. Este representa a perda de receitas por ter o capital investido em 
estoques em vez de tê-lo investido noutra atividade econômica. Uma interpretação comum é considerar o custo de manutenção de estoque de um produto como uma pequena parte do seu valor unitário.

Portanto a dimensão do estoque e o tempo que a mercadoria fica armazenada influência no custo de manutenção do estoque, por isso a relevância de analisar as demandas para dimensionar a quantidade de produtos a ser estocado e os prazos de entrega para que não ocorra a falta.

\section{Custo de Falta de Estoques}

Sob a ótica de Ballou (2006), os custos de falta de estoques ocorrem quando um pedido não pode ser atendido a partir do estoque ao qual é normalmente encaminhado. São dois os tipos principais desses custos: os das vendas perdidas e os de pedidos atrasados. Para Garcia et al. (2006):

Custos de falta são custos derivados de quando não existe estoque suficiente para satisfazer a procura dos clientes em um dado período. Como exemplo tem: pagamento de multas contratuais, perdas de venda, deterioração de imagem da empresa, perda de marketing, e utilização de planos de contingência.

Segundo Dias (2010), os custos de falta de estoques ou custo de ruptura podem ser determinados por meio de lucros cessantes, de custeios adicionais, custeios causados pelo não cumprimento dos prazos, quebra de imagem da empresa.

Para os autores o custo da falta de estoque deverá ser sempre considerado, já que o não atendimento pode causar impacto a curto, médio e longo prazo dependendo do ramo de atividade da organização, esses impactos podem ter uma maior proporção. Então o custo com falta de estoque deverá ser levantado e analisado sempre que ocorrer para que seja avaliado as consequências que causaram na organização e assim elaborar um plano de ação para corrigir o estoque de segurança.

\section{Sistemas de Controles de Estoques}

Dimensionar e controlar os estoques é um tema importante e preocupante. Descobrir fórmulas para reduzir estoques sem afetar o processo produtivo e sem o crescimento dos custos é um dos maiores desafios que os empresários estão encontrando.

Segundo Dias (1987) o controle de estoque otimiza os investimentos financeiros em estoques, aumenta o uso eficiente nas Empresas, e minimizar as necessidades de capital investido no estoque.

Então, estabelecer um bom controle de estoque vai muito além do que adquirir, saber quais materiais estão estocados e organizar a saída delas. Esse controle eficaz é de extrema relevância, uma vez que todo o estoque simboliza dinheiro da organização que foi investido e que pode resultar em grandes prejuízos, prejudicando consideravelmente a gestão financeira do negócio.

\section{Sistema Duas Gavetas}

Na visão de Dias (2010), o método de duas gavetas é o mais simples para controlar os estoques. Por sua simplicidade, é recomendável a utilização para as peças classe C. Tem seu uso bastante difundido em revendedores de autopeças e no comercio varejista de pequeno porte. 


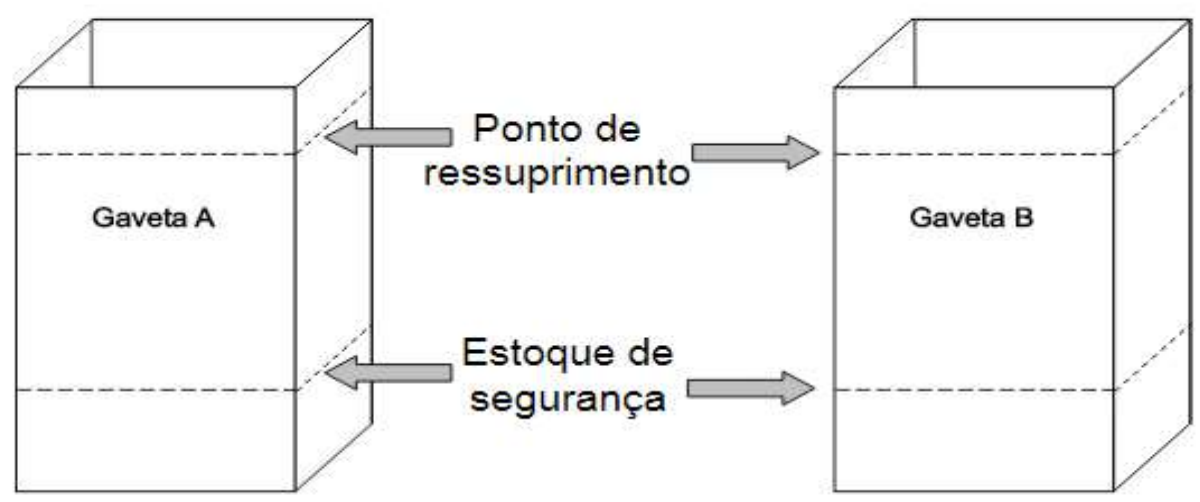

Fonte: Peinado (2017).

O estoque que inicia o processo é armazenado nessas duas caixas ou gavetas. A gaveta $\mathrm{A}$ tem uma quantidade de material suficiente para atender ao consumo durante o tempo de reposição, mais o estoque de segurança. A gaveta B possui um estoque equivalente ao consumo previsto no período.

As solicitações de material que chegam ao almoxarifado são atendidas pelo estoque da gaveta B; quando esse estoque chega a 0 (zero), isso indica que deverá ser providenciada uma reposição de material, pedido de compra. Para não interromper o ciclo de atendimento, passa-se a atender às solicitações pelo estoque da gaveta A. Nesse intervalo, deverá ser recebido o material comprado e completar o nível de estoque da gaveta A, e o saldo completar a gaveta B, voltando-se a consumir o estoque da gaveta B. A grande vantagem desse método consiste numa substancial redução do processo burocrático de reposição de material.

\section{Sistemas dos Máximos-Mínimos}

Para Dias (2010), se, para a reposição do estoque, soubéssemos o consumo exato do material num período predeterminado, a dificuldade de determinar um ponto de pedido não existiria; essas condições ideais são utópicas, porque o estoque estaria a "zero" assim que o material comprado fosse recebido.

Pelas dificuldades para determinação do consumo e pelas variações do tempo de reposição é que usamos o sistema de máximos e mínimos, também chamados de sistema de quantidades fixas. A principal vantagem desse método é uma razoável automatização do processo de reposição, que estimula o uso do lote econômico, em situações em que ele pode ser usado naturalmente, e abrange os itens das classes A, B e C. Segundo Ballou (2006), é um método adequado para ser usado quando a demanda é incerta, ou errática. A demanda incerta é quase sempre ligada a itens de movimentação lenta, mas não necessariamente a eles limitada.

O sistema máximo e mínimo poderá ser utilizado nos 3 tipos de classes de materiais, A, B e C, e funcionará a partir dos dados do estoque mínimo, máximo e de segurança para que assim determine o tempo de reposição, proporcionando a possibilidade de trabalhar de forma automatizado. Então a aquisição, a quantidade de consumo máximo e a quantidade que será utilizado em casos extremos serão a base de dados para utilizar esse método. 
Para organizações que estão em busca do melhor nível de estoque, redução de custo e com propósito de melhorar sua lucratividade, esse é um método que poderá ser realizado para gerenciar seus estoques, no entanto requer atenção aos tempos de reposições.

\section{Sistema das Revisões Periódicas}

Por esse sistema, o material é reposto periodicamente em ciclos de tempo iguais, chamados períodos de revisão. A quantidade pedida será a necessidade da demanda do próximo período. Considera-se também um estoque mínimo ou de segurança e ele deve ser dimensionado de forma que previna o consumo acima do normal e os atrasos de entrega durante o período de revisão e o tempo de reposição. (DIAS, 2010, p. 108)

Para o autor, nesse sistema, são programadas as datas em que deverão ser realizadas as reposições de material, e os intervalos são iguais. A análise deverá ser feita considerando o estoque físico existente, o consumo no período, o tempo de reposição e o saldo de pedido no fornecedor do item. A dificuldade desse método é a determinação do período entre revisões; diversos aspectos devem ser analisados.

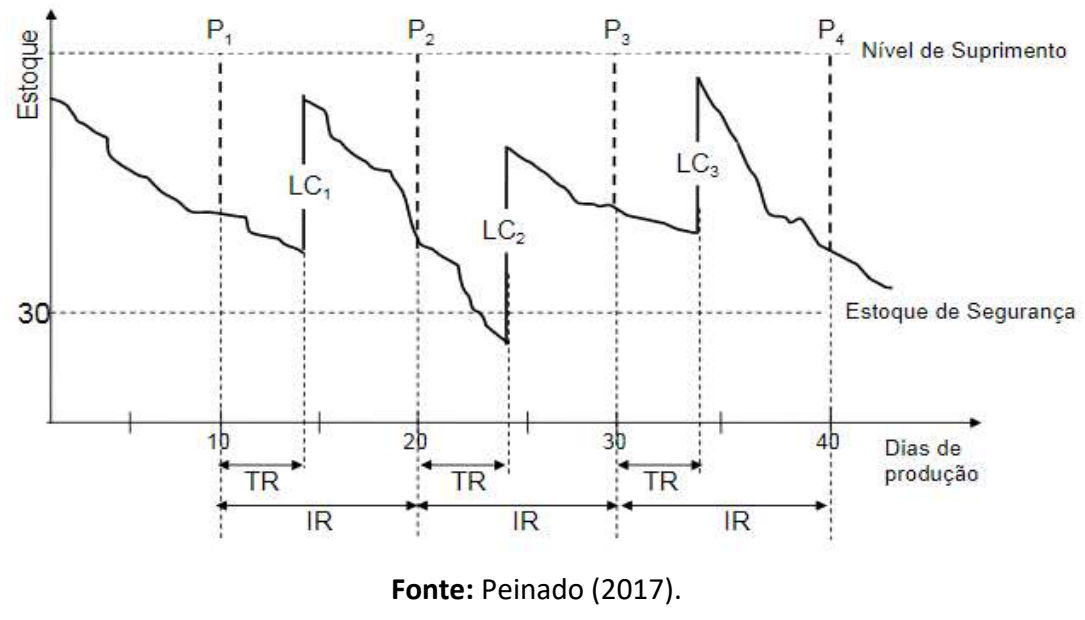

Para minimizar esses riscos devem ser calculadas revisões para cada material estocado ou para cada classe de materiais, de acordo com os objetivos operacionais e financeiros da empresa. A escolha de um calendário para as revisões é também de importância fundamental.

A vantagem de trabalhar com esse sistema é que ele permite formar grupos de mercadorias, simplificando o processo de aquisição para que ocorra em apenas um dia, mas não permite a utilização do lote econômico de compra, já que exige um estoque de segurança maior para um mesmo nível de produção se comparado a outro método.

\section{Sistema Materials Requirements Planinning - MRP}

Um dos sistemas de planejamento e controle de materiais mais divulgados é o MRP (Materials Requirements Planning). Originalmente conhecido através de Joseph Orlick, o MRP lida especialmente com suprimento de peças e componentes cujas demanda dependem de determinado produto. Os conceitos básicos do MRP existem há muito tempo, porém, com os sistemas informatizados, têm permitido às empresas beneficiarem-se dos métodos do MRP. 
Segundo Dias (2010), o MRP é um sistema que estabelece uma série de procedimentos e regras de decisão, de modo a atender às necessidades de produção numa sequência de tempo logicamente determinada para cada item componente do produto.

O sistema MRP é capaz de planejar as necessidades de materiais a cada alteração na programação de produção, registros de inventários ou composição de produtos, em outras palavras, trata-se de um sistema que se propõe a definir as quantidades necessárias e o tempo exato para utilização dos materiais na fabricação dos produtos.

O MRP fundamenta-se na emissão de pedidos de compras, que são calculadas a partir do planejamento de produção. Os pedidos de compras para esse sistema, só será gerado para atender as necessidades da produção e não para repor estoques. Esse sistema só emitirá pedido de acordo com o tempo de reposição registrado, fazendo com que o pedido chegue na hora e quantidade certa para produção. Por isso a importância de realizar um planejamento correto e determinar o tempo de reposição, já que o sistema funcionará de acordo com os dados registrados.

Utilizado para produção de produtos acabados e que durante o processo de fabricação depende de outras matérias-primas para sua composição, o sistema MRP é uma ferramenta que auxilia em caso de um replanejamento no processo sem causar impactos ao resultado, já enxerga as falhas e torna possível as correções em tempo hábil. Normalmente utilizado em empresas de grande porte.

\section{Sistema Just in Time}

Para Moreira (2008) "Jus in Time refere-se a uma das tentativas básicas de eliminar o desperdício, produzindo sempre a peça (ou produto, em geral) certa, no lugar certo, na hora certa". O JIT tem sido apresentado através de muitas definições que evoluem na medida de sua aceitação. Uma das mais comuns refere-se ao JIT como um método de redução de desperdícios nos processos de manufatura. Ao contrário da abordagem tradicional dos sistemas de produção, que "empurram" os estoques, o JIT caracteriza-se como um sistema de "puxar" a produção ao longo do processo, de acordo com a demanda (DIAS, 2010).

Moreira (2008) diz ainda que "as operações tradicionais de manufaturas são sistemas do tipo "empurrados". São baseados na ideia de que é melhor antecipar as necessidades futuras de produção e preparar-se para elas". Conforme Daniel (2008) "a lógica de um sistema puxado é simples: a comunicação no JIT começa ou com a última estação de trabalho na linha de produção ou com o cliente".

Genericamente falando, um sistema de "puxar" estoques significa que qualquer movimento de produção somente é liberado na medida da necessidade sinalizada pelo usuário da peça ou componente em fabricação, ou seja, os centros de trabalho não estão autorizados a produzir e "empurrar" os lotes apenas para manter ocupados operários e equipamentos.

O JIT também oferece o questionamento das normas estabelecidas, isto é, não convive passivamente com "níveis aceitáveis" de estoque, seja de matérias-primas produtos em processo ou acabados, de disponibilidade de máquina, de retrabalho, de refugo, de reclamação de clientes etc. 
Embora o entendimento dos conceitos do JIT seja de fácil absorção, na prática sua aplicação não é tão trivial como possa parecer à primeira vista. A dificuldade da administração em sincronizar a operação e as restrições de capacidade de processamento, confiabilidade e flexibilidade é uma das barreiras na implantação do JIT.

Logo, trabalhar com o Jus in Time consiste em estoque quase zero, já que o estoque existente será para atender as demandas cuja venda foi realizada, não gerando estoque parado. A classe $A$ seria a mais indicada para esse método devido ao preço unitário. A organização precisará ter uma boa interação e relacionamento com os fornecedores externos e internos para que o sistema obtenha sucesso, pois depende deles para atingir o nível de estoque mais baixo possível sem impactar no atendimento aos clientes.

\section{Sistema Kanban: Aplicação do JIT}

Para Dias (2010), o Kanban é uma das técnicas usadas para atingir a meta do JIT. Não se trata de um sinônimo. Kanban é um instrumento que utiliza como filosofia os conceitos do JIT. A palavra Kanban é de origem japonesa e significa cartão. A orientação da técnica do Kanban é no sentido de se reduzir os tempos de partida de máquina e os tamanhos dos lotes e produzir apenas a quantidades necessárias à alimentação da demanda. Alguns defendem a preferência pelo sistema Kanban ao MRP, por suas características de simplicidade e custo e por se tratar de um sistema de "puxar estoques".

Uma das limitações do Kanban é que ele produz apenas aquelas partes cuja demanda é regular e, pelo menos, diária. Outra limitação diz respeito à intensa preparação requerida para implantação do sistema. Sem uma forte disciplina e treinamento, dificilmente obtém-se sucesso com o sistema Kanban.

O sistema propicia fluxos de produção mais uniformes e a oportunidade de fazer melhoramentos. O Kanban reduz o material em processo até o mínimo absoluto. Além disso, há uma preocupação constante de reduzir o lead time e o setup das máquinas.

\section{Classificação ABC}

A curva $A B C$, conforme Chiavenato (2005), também conhecida como Curva de Pareto é baseada no princípio de que maior parte de investimento em materiais está concentrada em um pequeno número de itens. Para Dias (2010), a curva $A B C$ é um importante instrumento para o administrador; ela permite identificar aqueles itens que justificam atenção e tratamento adequados quanto à sua administração. Obtémse a curva $A B C$ através da ordenação dos itens conforme a sua importância relativa.

Verifica-se, portanto, que, uma vez obtida a sequência dos itens e sua classificação $A B C$, disso resulta imediatamente a aplicação preferencial das técnicas de gestão administrativa, conforme a importância dos itens. A curva $A B C$ tem sido usada para a administração de estoques, para a definição de políticas de vendas, para o estabelecimento de prioridades, para a programação da produção e uma série de outros problemas usuais nas empresas.

A uniformidade dos dados coletados é de primordial importância para a consistência das conclusões da curva $A B C$, principalmente quando estes dados são numerosos. Nesse caso, é interessante fazer uma 
análise preliminar após o registro de uma amostra de dados para verificar a necessidade de estimativas, arredondamentos e conferências de dados, a fim de padronizar as normas de registro. Em seguida, conforme a disponibilidade de pessoal e de equipamentos deve ser programada a tarefa de cálculos para obtenção da curva $A B C$, utilizando-se meio de cálculo manual ou um software adequado.

\section{CONCLUSÃO}

Os estudos realizados nos permitem compreender que o controle de estoque nas empresas é fundamental para a diminuição dos custos de uma entidade independentemente do seu porte. É sabido que estoque elevados e mal administrados encarecem o preço final dos produtos, bem como uma aplicação indevida do capital de giro.

Os estoques estão localizados em todos os níveis da cadeia de suprimentos, desde as fontes de fornecimento até o cliente final, incluindo os estoques existentes dentro das fábricas, nos depósitos e durante o transporte. A redução dos estoques melhora o fluxo de caixa e o retorno sobre os investimentos.

Considera-se que a Gestão de Estoques é um instrumento da administração que planeja, controla e replaneja todo fluxo de mercadorias, de acordo com a demanda, fundamentada nas necessidades dos clientes, de forma rápida e com eficiência. Essa com foco na redução de custos e o aumento da rentabilidade da organização.

A empresa deve identificar qual tipo de estoque possui, e assim poderá controlar os custos gerados por ele, trabalhando a fragilidade que está exposta, reduzindo os riscos e apontando a quantidade do pedido de reposição de um item no estoque. Deverão ser analisados e dimensionados os impactos que causam no preço do produto e na organização os custos gerados na aquisição, manutenção e falta de estoques

O princípio do controle de estoque dimensionará o nível de estoque de segurança sem gerar prejuízos no programa de produção e nas vendas, mas para que isso aconteça será necessário utilizar o método adequado para o controle do estoque, como: Sistema duas gavetas, Sistema dos máximos-mínimos, Sistemas das revisões periódicas, Sistema MRP, Sistema Just in Time, Sistema KARBAN e a classificação ABC.

Logo, as empresas devem buscar o aprimoramento dos fatores relacionados ao processo de gerenciamento de seu estoque. Sabe-se que pessoas, cidades, estados países e continente estão continuamente intercambiando produtos e serviços nos quais cada parte de o excedente daquilo que sabe e a outra compra segundo as suas necessidades, aquilo que tem pouco que não sabe produzir. Cabe ao administrador compreender que quanto melhor forem os controles de estoque e seu gerenciamento, o processo produtivo terá mais agilidade e flexibilidade.

\section{REFERÊNCIAS}

ARNOLD, J. R. T.. Administração de Materiais. São Paulo: Atlas, 1999

BALLOU, R. H.. Gerenciamento da Cadeia de Suprimentos: Logística Empresarial. Porto Alegre: Bookman, 2006.
CABRAL, J. S.. Organização e gestão da manutenção: dos conceitos à prática. 3 ed. Lisboa: Lidel, 1998.

CHIAVENATO, I.. Administração de Materiais: uma abordagem introdutória. Rio de Janeiro. Rio de Janeiro: Elsevier, 2005. 
DEMO, P.. Pesquisa: Princípios científicos e educativos. 7 ed. São Paulo: Cortez, 2000

DIAS, M. A. P.. Transporte e Distribuição Física. São Paulo: Atlas, 1987

DIAS, M. A. P.. Administração de Materiais: Princípios, conceitos e gestão. 6 ed. São Paulo: Atlas, 2005.

DIAS, M. A. P.. Administração de Materiais uma abordagem Logística. São Paulo: Atlas, 2010.

SEVERO FILHO, J.. Administração de logística integrada: materiais, PCP e marketing. Rio de Janeiro: E-papers, 2006.

GARCIA, E. S.; REIS, L. M. T. V.; MACHADO, L. R.; FERREIRA, V. J. M.. Gestão de estoques: otimizando a logística e a cadeia de suprimentos. Rio de Janeiro: E-papers, 2006.

GIL, A. C.. Métodos e Técnicas de Pesquisa Social. 6 ed. São Paulo: Atlas, 2008.

LEONE, G. S. G.. Curso de Contabilidade de Custos. São Paulo: Atlas, 1997.

MARCONI, M. A.; LAKATOS, E. M.. Técnicas de pesquisa: planejamento e execução de pesquisas, amostragens e técnicas de pesquisas, elaboração, análise e interpretação de dados. 6 ed. São Paulo: Atlas, 2007.

MARTINS, G. A.; PINTO, R. L.. Manual para elaboração de trabalhos acadêmicos. São Paulo: Atlas, 2001.
MOREIRA, D. A.. Administração da Produção e Operações. 2 ed. São Paulo: Cengage Learning, 2008.

NAKAGAWA, M.. Gestão estratégica de custos. São Paulo: Atlas, 1993

NEVES, J. L.. Pesquisa qualitativa-características, usos e possibilidades. Caderno de Pesquisa em Administração, v.1, n.3, 1996

Peinado, J.. Gestão de operações: Métodos de ressuprimentos, estoques de segurança. 2013.

SEVERINO, A. J.. Metodologia do trabalho científico. 23 ed. São Paulo: Cortez, 2007

SHINGO, S.. O Sistema Toyota de produção: ponto de vista da engenharia de produção. 2 ed. São Paulo: Bookman, 1996.

SLACK, N.; CHAMBERS, S.; JOHNSON, R.. Administração da produção. São Paulo: Atlas, 1997.

SLACK, N.; CHAMBERS, S.; JOHNSON, R.. Administração da Produção. 2 ed. São Paulo: Atlas, 2007.

TUBINO, D. F.. Manual de planejamento e controle da produção. 2 ed. São Paulo: Atlas, 2000.

WERKEMA, M. C. C.. As ferramentas da qualidade no gerenciamento de processos. Belo Horizonte: EdUFMG, 1995.

A CBPC - Companhia Brasileira de Produção Científica (CNPJ: 11.221.422/0001-03) detém os direitos materiais desta publicação. Os direitos referem-se à publicação do trabalho em qualquer parte do mundo, incluindo os direitos às renovações, expansões e disseminações da contribuição, bem como outros direitos subsidiários. Todos os trabalhos publicados eletronicamente poderão posteriormente ser publicados em coletâneas impressas sob coordenação da Sustenere Publishing, da Companhia Brasileira de Produção Científica e seus parceiros autorizados. Os (as) autores (as) preservam os direitos autorais, mas não têm permissão para a publicação da contribuição em outro meio, impresso ou digital, em português ou em tradução. 